\title{
Comprehensive e-Learning System with Simulation Capabilities for Understanding of Complex Equations
}

\author{
Kohei $\mathrm{Arai}^{1}$ \\ Graduate School of Science and Engineering \\ Saga University, Saga City, Japan
}

\begin{abstract}
A comprehensive e-learning system with simulation capabilities for understanding of complex equations is proposed. Through experiment with the proposed e-learning system, it is found that the proposed system is much effective and comprehensive than the conventional e-learning system without any mathematical expressions of processing and simulation capabilities by $14.5 \%$, the time required for learning increased by $18.2 \%$ though. In addition, the proposed system not only helps students to understand subjects and complex equations but also can be effective to increase students' motivation to learn.
\end{abstract}

Keywords-SCORM; e-learning; simulation; Physics subject; action script

\section{INTRODUCTION}

The use of e-learning is increasing every year. Convenient tools have been provided. Standardization is being promoted by various organizations. SCORM (Sharable Content Object Reference Model) is one of those which is advocated by ADL (Advanced Distributed Learning). There are some standardized e-learning systems such as AICC (Aviation Industry Computer-Based Training Committee), SCORM, and XAPI/Tin Can API (the successor to SCORM) SCORM.

SCORM $^{1}$ is a standard adopted worldwide. Its aims are reusability, accessibility, interoperability, and tolerance. Meanwhile, The $\mathrm{AICC}^{2}$ is dissolved, but having an LMS that supports AICC is still crucial. These universal specifications set forth by the AICC soon reached far beyond the aviation community and into the corporate training world, making AICC the first e-learning standard in the world.

The SCORM standard is all about tracking the status of big and chunky e-learning modules, with the e-learning module and the learner record usually residing in a single LMS or Learning Management System. Tin Can API ${ }^{3}$ however, rightly recognizes that most learning happens away from the LMS. So the focus has moved away from e-learning modules towards learning activities, be these offline or online, tutor-led or collaborative, real-world or virtual. It doesn't matter where the activity takes place; what matters is that some remote system with knowledge of that activity can send a simple statement to a central learner record store (LRS) containing some very basic details of what the learner did.

In these standardized e-learning system, comprehensive e-

\footnotetext{
${ }^{1}$ https://elearningindustry.com/primer-youll-need-elearning-standardsscorm-xapi-aicc

${ }^{2}$ https://www.elearninglearning.com/aicc/

${ }^{3} \mathrm{http}: / /$ www.open-thoughts.com/2012/10/understanding-tin-can-api/
}

learning contents and procedure as well as processes have to be provided for improving learning performance. Most of elearning contents for scientific subjects such as mathematics, physics, chemistry, etc. provide formula directly to learners even if the learners are not good at mathematics. It is not comprehensive at all. Therefore, comprehensive e-learning contents and procedure as well as processes in particular for Newtonian equation subject as just an example in this paper.

In order to create a comprehensive e-learning, the proposed e-learning system provides simulation capabilities. There are other ways for improving comprehensiveness of elearning contents for the lessons of the Newtonian equation. Virtual Reality: VR, Augmented Reality: AR based approaches are typical ways. Motion based Human-Computer interaction based approaches are another ways. The proposed e-learning system can be used together with these typical ways of learning processes, procedure and contents. Namely, the proposed e-learning system provides simulation capabilities followed by AR, VR as well as motion based HCI utilizing system.

The purpose of this research is to develop a comprehensive e-learning system that enables mathematical expression processing and simulation, and to confirm the effect of the developed system. Students can understand complex equations by using simulation capabilities which are included in the proposed e-learning system. It is possible that the coefficients in the complex equations can be changed and also look at the simulation results easily. Thus the students can understand the meaning of the complex equations. The proposed function added to the proposed e-learning system is based on SCORM standard obviously.

The following section describes research background and related research works as well as the proposed method and system followed by the method of experiments. Then the experimental results are described together with some remarks. Finally, conclusion is described together with some discussions and future research works.

\section{RELATED STUDIES AND RESEARCH BACKGROUND}

The eLearning Designer's Handbook: A Practical Guide to the eLearning Development Process for New eLearning Designers 1st Edition was published for fundamentals of elearning system design and e-learning content creations [1]. Adaptation of composite e-learning contents for reusable in smartphone based on learning system is proposed for comprehensive and convenient e-learning system for mobile 
learners [2]. Practical report on hybrid learning with elearning and simulation is reported for confirmation of effectiveness of simulations in e-learning [3]. Instructional design for e-learning practice is reported for enhancing an effectiveness of simulations in e-learning [4].

\section{PROPOSED METHOD}

\section{A. Basic Design Concept of the Proposed e-learning System}

The basic design concept and the feature of the proposed e-learning system is as follows:

1) Client-Server Model

2) PHP based programing for user interface

3) C programing language is available for users

4) There are three major capabilities, simulation functions (sim.php), data handling (data.php), and data deletion (del.php)

5) Web based browser with Flash

Students can use the proposed e-learning system through Web browser in comprehensive manner. There are many simulation software tools under the sim.php. Therefore, students may use one of the simulation software on their own. If students would like to create their own simulation software tools, they can use the $\mathrm{C}$ programing language and register their simulation software tools in the sim.php. Meanwhile, they can use the data under the data.php for simulations. Also, they can delete the data through the del.php.

\section{B. Proposed e-Learning System and Procedure}

Fig. 1 shows the proposed e-learning system configuration and procedure. It is essentially client-server model. In the server side, sin.php, data.php, del.php are stored together with c programs. On the other hand, Flash based display functionality with web browser is functioned in the client side as shown in Fig. 1(a). Input parameters are input from the client side as shown in Fig. 1(b). Then parameters are transferred to c programs as files as shown in Fig. 1(c). In the same time, coordinate data is created in the server as shown in Fig. 1(d). After that, the coordinate data is transferred as the files as shown in Fig. 1(e). Then, the data file name is transferred to the client side as shown in Fig. 1(f). The data is, then, transferred to server side of data.php as shown in Fig. $1(\mathrm{~g})$. At the same time, coordinate data is transferred to data.php from the file as shown in Fig. 1(h).

Fig. 1(i) shows coordinate data transfer to client followed by execution of the simulator as shown in Fig. 1(j). Then, data file name is transferred to del.php as shown in Fig. 1(k) followed by data storing through del,php in the files as shown in Fig. 1(1). This is the proposed e-learning system with simulation capability and its procedure.
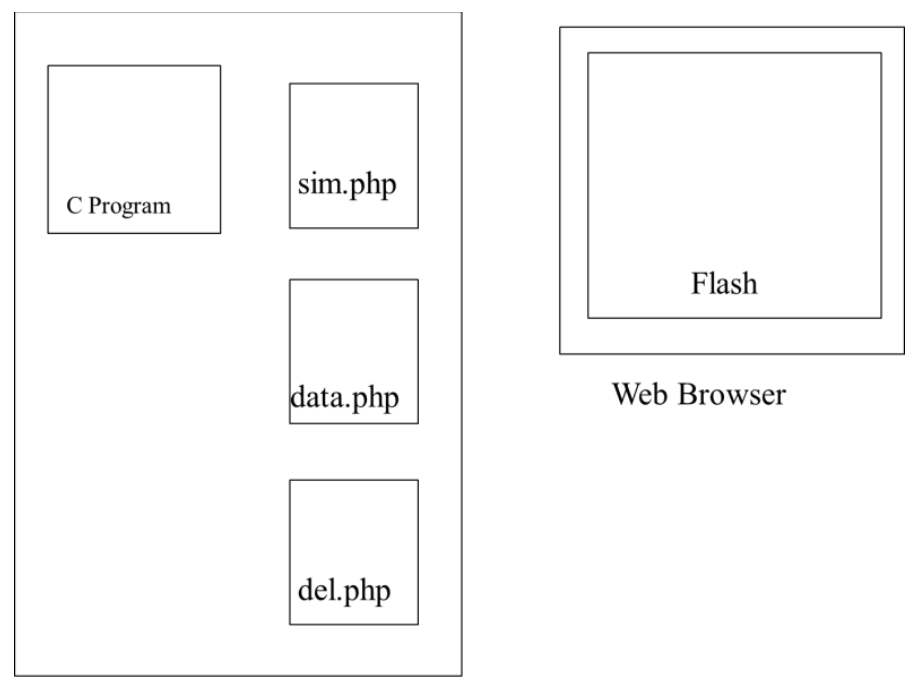

Server side

(a) Client-Server based e-Learning System.

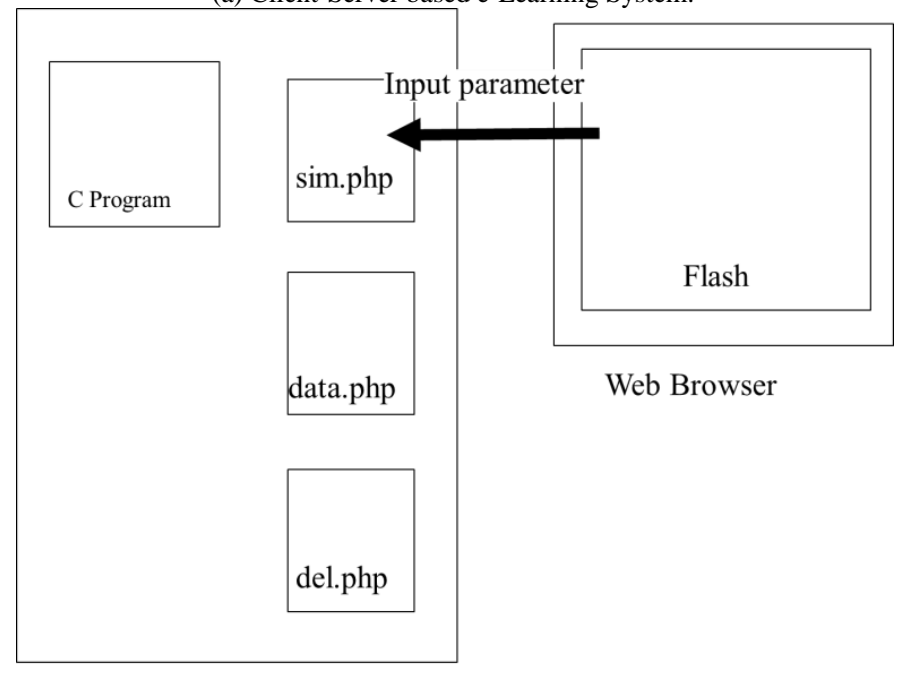

Server side

(b) Input Parameter.

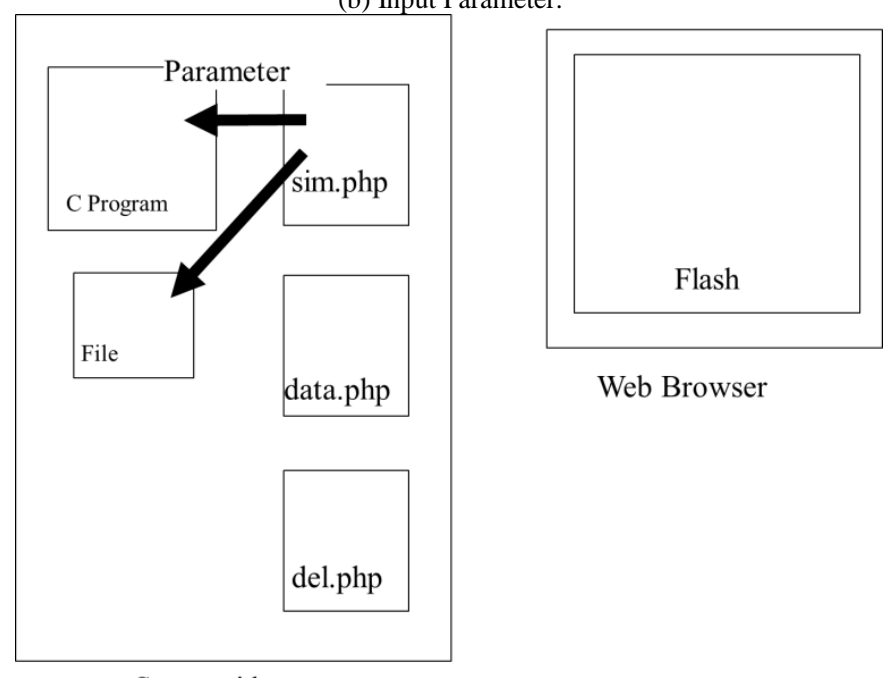

Server side

(c) Parameter Files. 


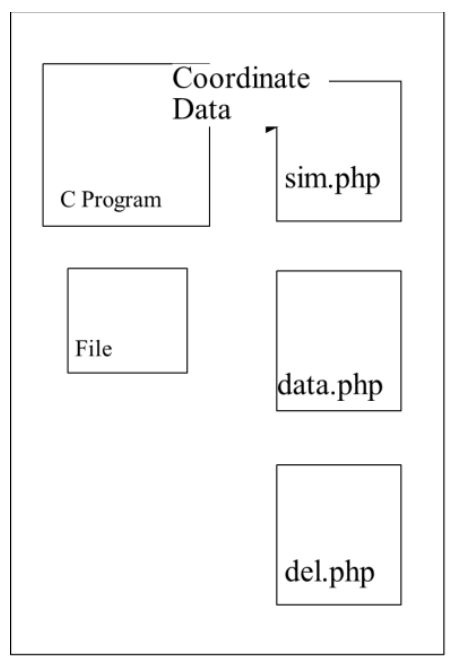

Server side

(d) Coordinate Data.

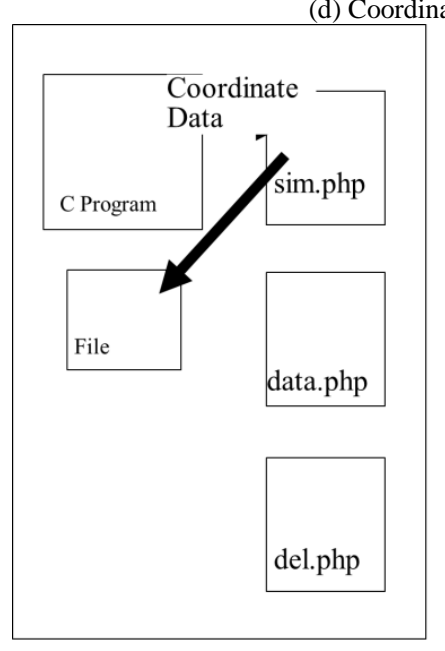

Server side

(e) Coordinate Data Transfer.

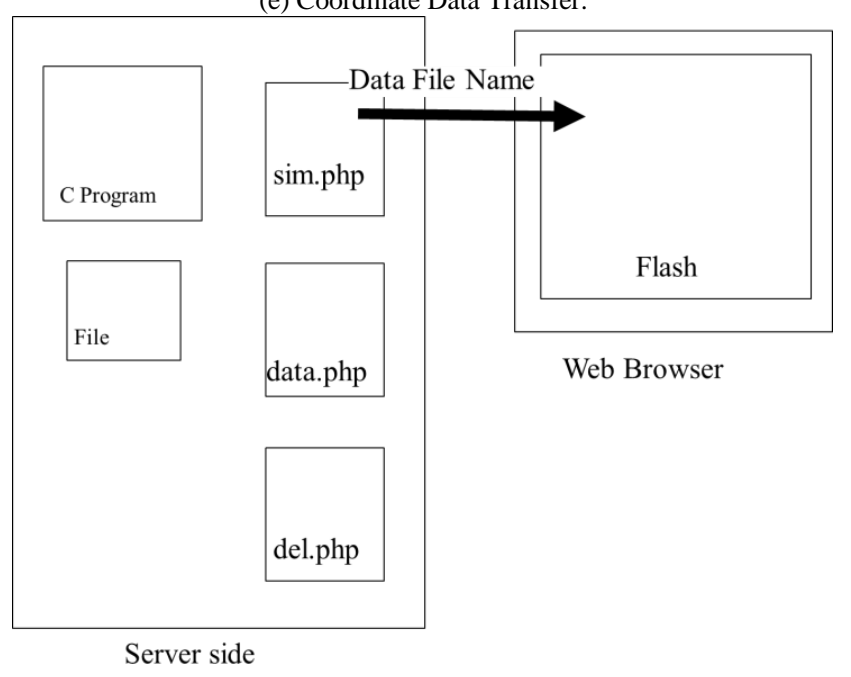

(f) Data File Name.

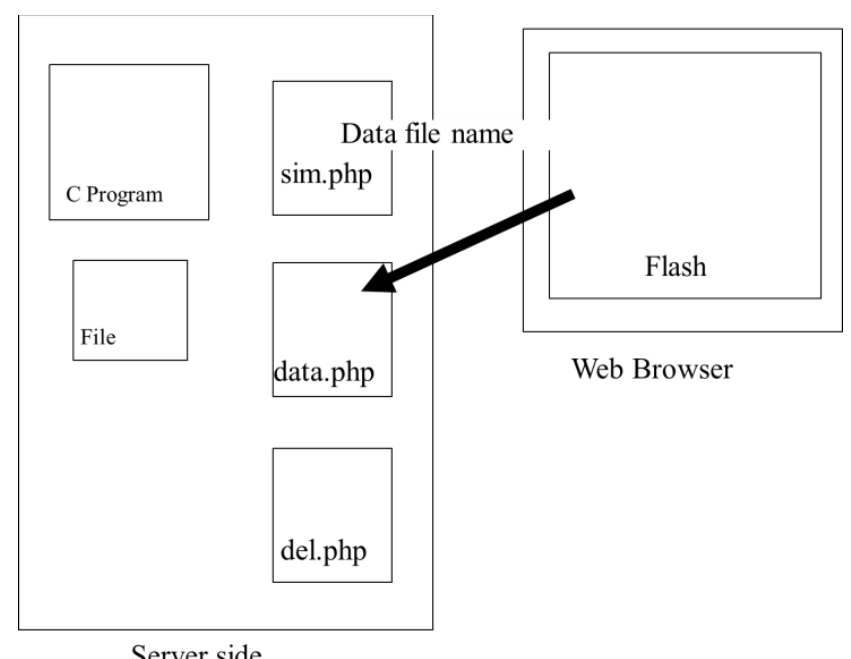

Server side

(g) Data Transfer.

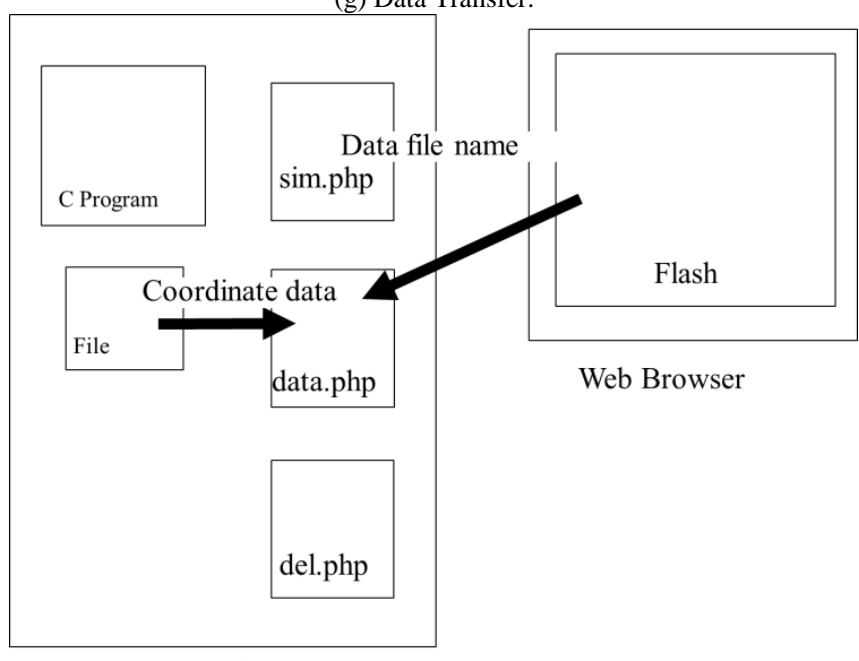

Server side

(h) Coordinate Data from the Files.

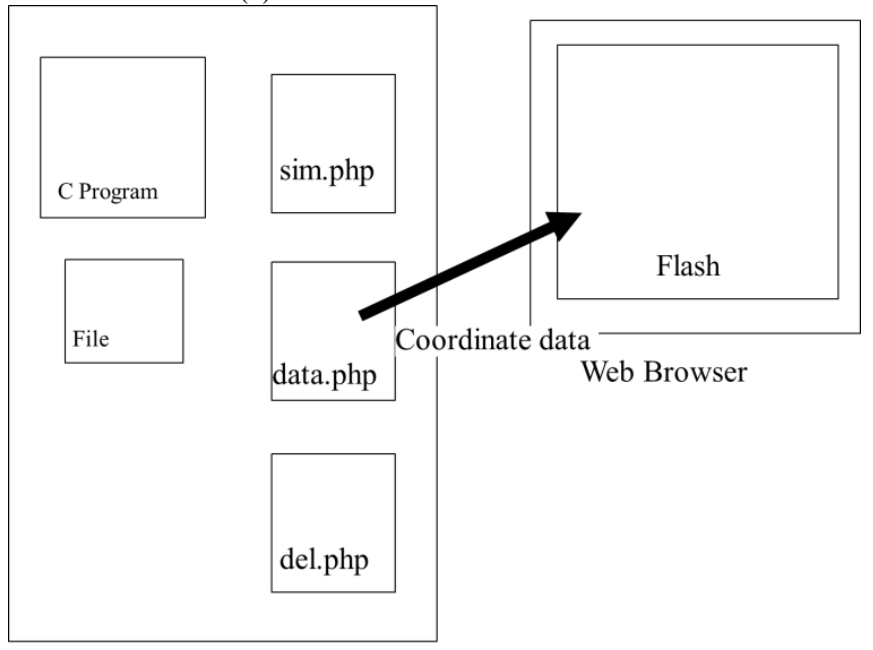

Server side

(i) Coordinate Data Transfer to Client. 


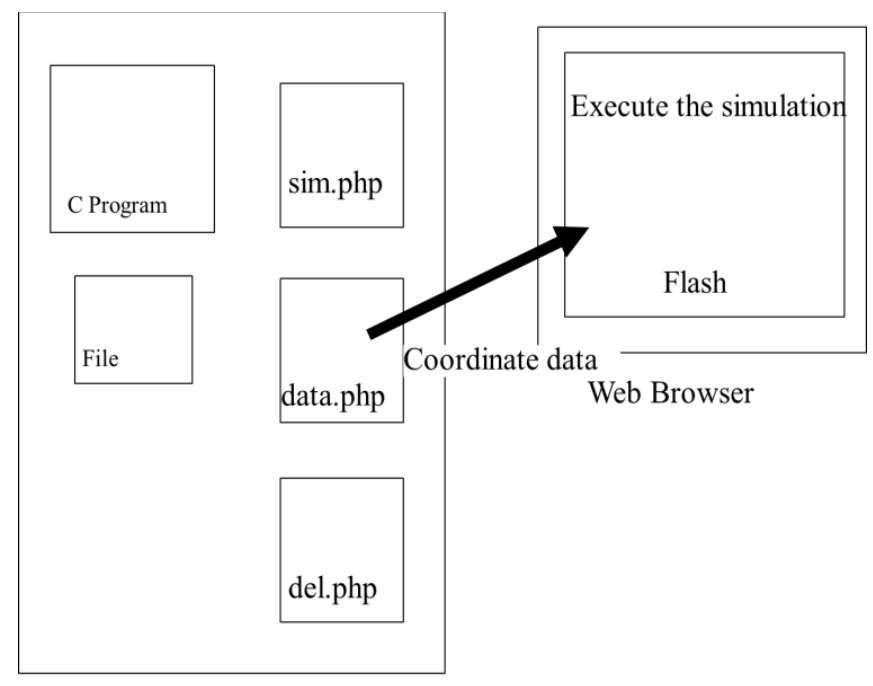

Server side

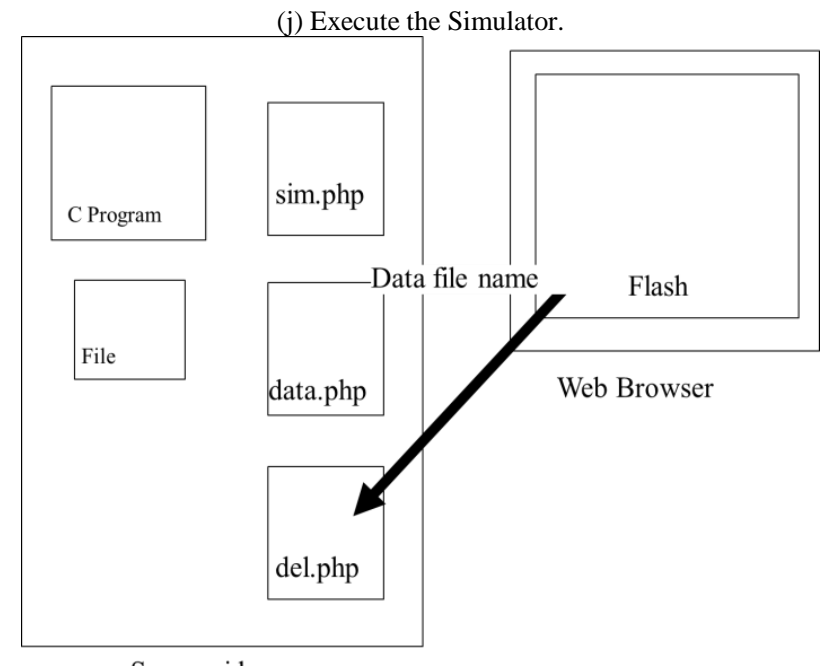

Server side

(k) Data File Name is Transferred to Del.php.

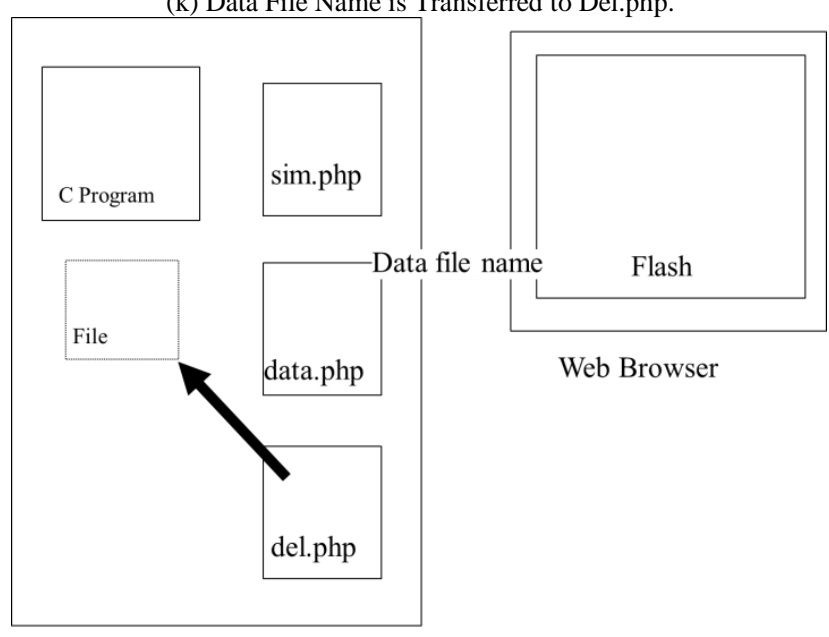

Server side

(1) Data is Stored Through Del,php in the Files.

Fig. 1. Proposed e-Learning System with Simulation Capability and its Procedure.

\section{Software Tools and Language used}

The tools and language used are as follows.

FlashMX ${ }^{4}$ (ActionScript)

User interface

PHP $^{5}$

File operation

Interface between Flash and $\mathrm{C}$ program

$\mathrm{C}, \mathrm{C}++$

FlashMX (ActionScript) can create simple animations to complex web applications. The SWF: Small Web Format / Shockwave Flash ${ }^{6}$ file made with FLASH-MX can be seen if Flash player (free distribution) is installed. The penetration rate is high (98\%). It can be displayed in the same manner on various platforms and browsers, and it is difficult to be influenced by the user's environment.

PHP is free software, there is no need to compile. Also, grammar is similar to $\mathrm{C}$ language, easy to understand. In addition, it is a server side script, not dependent on the user's environment.

In this way, since data exchange and file operation between programs are performed by PHP, the system can be reused relatively easily. Fig. 2 shows an example of the snap shot image of the client display.

\section{Learning Procedure}

Firstly, students choose the subject to learn. The descriptions, the content, and the video content are displayed onto e-learning system display. The description usually contains complex equations. It is not always that the equations are comprehensive. Therefore, students may try to use simulation software tool under the sim.php. Once students choose one of the simulation software tools in the simulation software tool database, the coefficients in the equations can be changed through dialog box in the Web browser. Then, simulation results can be displayed after the simulations. Therefore, students can understand the meaning of the equations in a comprehensive manner.

\section{E. Example of Simulation}

One of the examples is introduced here. That is simulating the movement of a satellite around the earth. Students can set the distance from the center of the earth and initial velocity when the artificial satellite is laid horizontally on the ground.

The movement of the artificial satellite around the earth is a two-body problem. The equation of the universal gravitational force acting on the satellite of the mass $m$ is expressed as the motion relating to the relative coordinate vector $r$ of the artificial satellite as follows.

$\mathrm{m} \frac{d^{2} t}{d t^{2}}=-\frac{G M m}{r^{2}} e_{r}$

\footnotetext{
${ }^{4} \mathrm{https}: / / \mathrm{www}$. updatestar.com/ja/topic/flash\%20 $\mathrm{mx} \% 20$ 無料

${ }^{5} \mathrm{http}: / /$ php.net/manual/ja/intro-whatis.php

${ }^{6}$ https://dic.nicovideo.jp/a/swf
} 


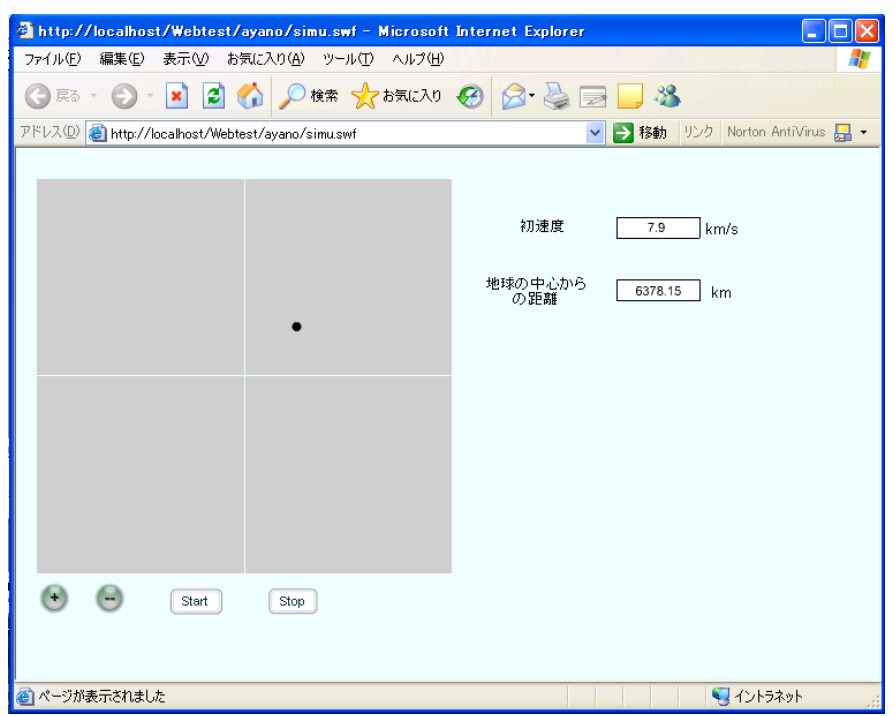

Fig. 2. Example of the Snap Shot Image of the Client Display.

where, $e_{r}=\boldsymbol{r} / r$ is the unit vector in the direction $r, G=$ $6.67259 \mathrm{e}^{-11} \mathrm{Nm}^{2} / \mathrm{kg}^{2}$ is the gravitational attraction constant, $m$ is the mass of the satellite, $M=5.9742 \mathrm{e}^{+24} \mathrm{~kg}$ is the mass of the earth, $r$ is the equatorial diameter. It is the distance between the center of the earth of $12,756.3 \mathrm{~km}$ and the artificial satellite. The satellite size shall be negligibly small. When the above equation is expressed by $(x, y)$ coordinates,

$F_{x}=-G M m \frac{x}{r^{3}}$

$F_{y}=-G M m \frac{y}{r^{3}}$

However, the radius of the earth is $r=\sqrt{x^{2}+y^{2}}$. From this equation of motion,

$\frac{d x}{d t}=v_{x} m \frac{d v_{x}}{d t}=-\frac{G M m x}{\left(x^{2}+y^{2}\right)^{3 / 2}}$

$\frac{d y}{d t}=v_{y} m \frac{d v_{y}}{d t}=-\frac{G M m y}{\left(x^{2}+y^{2}\right)^{3 / 2}}$

It can be represented by simultaneous differential equation. If students change the initial speed from this formula using the Euler method ${ }^{7}$, Runge-Kutta method ${ }^{8}$, students can draw various satellite orbits. In order to fly satellites orbiting the earth on the earth's surface, a speed of about $7.9 \mathrm{~km} / \mathrm{s}$ is required, which is called the primary space velocity. Although these equations are not comprehensive, variables in the equations can be changed and simulation results can be made available to display results in these equations are going to be understandable comprehensively.

On the other hand, the following questions are effective for deep understanding of the Newtonian equations.

\section{F. Examples of the Questions in a Lesson}

Examples of the questions in a lesson for Newtonian equation are as follows:

\footnotetext{
${ }^{7}$ http://lpsa.swarthmore.edu/NumInt/NumIntFirst.html

${ }^{8}$ https://en.wikipedia.org/wiki/Runge-Kutta_methods
}

\section{- Question 1}

In the above-mentioned differential equation, the earth escape speed is about $7.9 \mathrm{~km} / \mathrm{s}$, and check the satellite orbit by the program to solve this by the Euler method and the Runge-Kutta method. However, there is no need to consider air resistance.

\section{- Question 2}

Consider the result of the trajectory obtained at various initial velocities.

- Question 3

Change the step size of the Euler method and the RungeKutta method, and investigate the change of the trajectory. Consider the difference in the results of the trajectory calculation.

One of the answers of the satellite orbit trajectory is as follows. Fig. 3 shows the locus of the artificial satellite turning around the earth solved by Runge-Kutta method.

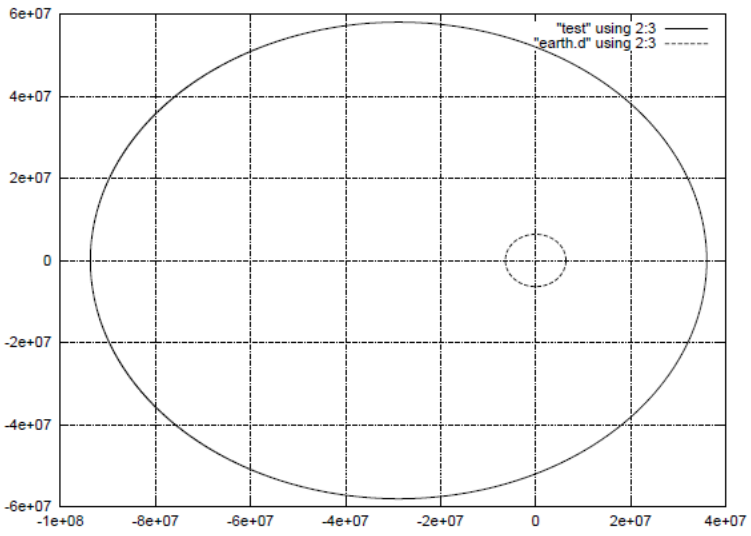

Fig. 3. The Locus of the Artificial Satellite Turning Around the Earth Solved by Runge-Kutta Method.

Thus, the students may understand the meaning of the equations comprehensively and deeply by changing the variables in the equations.

\section{EXPERIMENT}

Achievement tests were conducted with and without the system created. The 10 questions are there in the achievement test. I also conducted 10 subjects and compared the results. Table I and Fig. 4 shows the achievement test result.

Most of the students gained their score about 9 point with the standard deviation of 14.491 when they use the simulation function. The time required for lesson, however, is increased about 34.3 in average with the standard deviation of 133.911 when they use simulation function.

When using simulation function Compared to when not in use, Eight out of ten people increased (maintain) the score. In addition, learning time has increased more than half. For those who reduced the score when using the simulation function, both the average score and average learning time increased. The reason why the average point rose was thought to be that it was easier to intuitively understand the movement of the artificial satellite by using the simulation function. 
Regarding the increase in learning time, it is conceivable that simulation must be executed in addition to learning by text, and that the motivation for students' learning has improved due to the addition of a simulation function. Moreover, the tendency that the original score is slightly higher is seen for those who have decreased learning time. Furthermore, I think that the second motivation to learn has been deprived because I took high score earlier.

From the table, it is found that the probability of obtaining a high score is higher as the percentage of learning time with simulation is larger. Moreover, the relation between the time required for lesson and their score without simulation functionalities shows less dependency on the students' potential capabilities ( $R$ square value is less than 0.3 ) while that with simulation functionalities shows much large dependency ( $\mathrm{R}$ square value is greater than 0.5). This implies that lessons with simulation capabilities give the students very well understandings comprehensively about the Newtonian equations through attractive learning processes.

TABLE. I. ACHIEVEMENT TEST Result

\begin{tabular}{|l|l|l|l|l|l|l|}
\hline & \multicolumn{2}{|l|}{ Without Sim. } & \multicolumn{2}{l|}{ With Sim. } & \multicolumn{2}{l|}{$\begin{array}{l}\text { Difference BTW } \\
\text { Both }\end{array}$} \\
\hline $\begin{array}{l}\text { Student } \\
\text { No. }\end{array}$ & $\begin{array}{l}\text { Required } \\
\text { time }\end{array}$ & $\begin{array}{l}\text { Scor } \\
\text { e }\end{array}$ & $\begin{array}{l}\text { Required } \\
\text { time }\end{array}$ & $\begin{array}{l}\text { Scor } \\
\text { e }\end{array}$ & $\begin{array}{l}\text { Required } \\
\text { time }\end{array}$ & $\begin{array}{l}\text { Scor } \\
\text { e }\end{array}$ \\
\hline 1 & 214 & 70 & 175 & 60 & -39 & -10 \\
\hline 2 & 204 & 70 & 387 & 90 & 183 & 20 \\
\hline 3 & 208 & 60 & 246 & 70 & 38 & 10 \\
\hline 4 & 307 & 70 & 117 & 60 & -190 & -10 \\
\hline 5 & 197 & 70 & 372 & 70 & 175 & 0 \\
\hline 6 & 209 & 60 & 246 & 70 & 37 & 10 \\
\hline 7 & 220 & 50 & 108 & 60 & -112 & 10 \\
\hline 8 & 56 & 60 & 260 & 70 & 204 & 10 \\
\hline 9 & 105 & 40 & 221 & 80 & 116 & 40 \\
\hline 10 & 275 & 70 & 226 & 80 & -49 & 10 \\
\hline Average & 199.5 & 62 & 235.8 & 71 & 36.3 & 9 \\
\hline St.Dev. & 72.724 & 10.32 & 92.294 & 9.94 & 133.911 & 14.4 \\
\hline
\end{tabular}

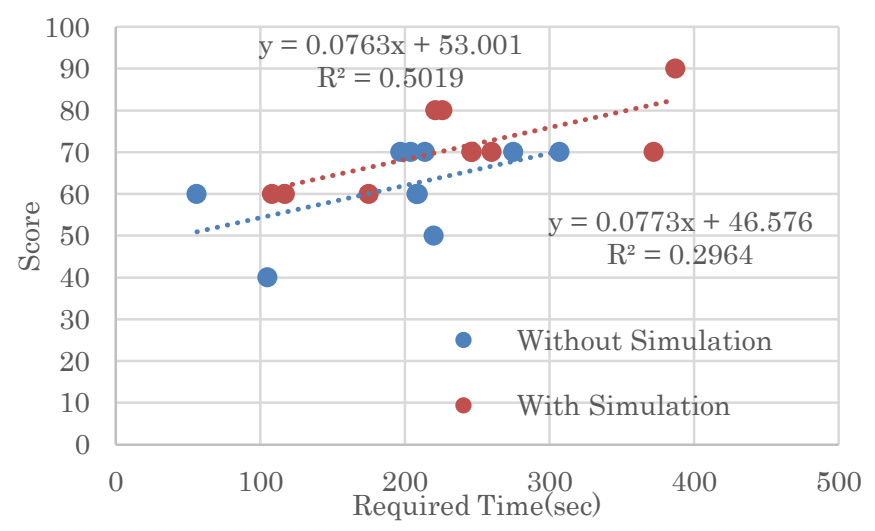

Fig. 4. Achievement Test Result.

\section{CONCLUSION}

A comprehensive e-learning system with simulation capabilities for understanding of complex equations is proposed. Through experiment with the proposed e-learning system, it is found that the proposed system is much effective and comprehensive than the conventional e-learning system without any mathematical expressions of processing and simulation capabilities by $14.5 \%$, the time required for learning increased by $18.2 \%$ though. In addition, the proposed system not only helps students to understand subjects and complex equations but also can be effective to increase students' motivation to learn.

Experimental results show that the e-learning system using the simulation function is effective for the learning of the mathematical system. In addition, this system not only helps students to understand but also can be said to be effective in terms of "motivation to learn".

Further investigations are required for another simulation capability with another subject.

\section{ACKNOWLEDGMENT}

The author would like to thank Keiko Ayano for her effort to conduct the experiments.

\section{REFERENCES}

[1] Tim Slade, The eLearning Designer's Handbook: A Practical Guide to the eLearning Development Process for New eLearning Designers 1st Edition, ISBN-10: 1983447439, 1983.

[2] Herman Tolle Kohei Arai, Aryo Pinandto, Adaptation of Composite ELearning Contents for Reusable in Smartphone Based on Learning System, Proceedings of the International Conference on Advanced Computer Science and Information Systems 2014, 502-507, DOI101109/ICANSIS 2014, 7065895, IEEE, 2014.

[3] Yoshikazu Hamada, Yoshihiko Suzuki, Go Hasegawa: "Practical Report on Hybrid Learning with e-Learning and Simulation", Research Report of Educational Systems Information Society, Vol.27, No.1, pp.77-80, 2012.

[4] Katsuaki Suzuki, "Instructional Design for e-Learning Practice", Journal of Japan Society for Educational Technology, Vol.7, No.3, pp.197-205 2005 .

\section{AUTHOR's PROFILE}

Kohei Arai, He received BS, MS and PhD degrees in 1972, 1974 and 1982, respectively. He was with The Institute for Industrial Science and Technology of the University of Tokyo from April 1974 to December 1978 also was with National Space Development Agency of Japan from January, 1979 to March, 1990. During from 1985 to 1987, he was with Canada Centre for Remote Sensing as a Post Doctoral Fellow of National Science and Engineering Research Council of Canada. He moved to Saga University as a Professor in Department of Information Science on April 1990. He was a councilor for the Aeronautics and Space related to the Technology Committee of the Ministry of Science and Technology during from 1998 to 2000 . He was a councilor of Saga University for 2002 and 2003. He also was an executive councilor for the Remote Sensing Society of Japan for 2003 to 2005. He is an Adjunct Professor of University of Arizona, USA since 1998. He also is Vice Chairman of the Science Commission "A" of ICSU/COSPAR since 2008 then he is now award committee member of ICSU/COSPAR. He wrote 37 books and published 570 journal papers. He received 30 of awards including ICSU/COSPAR Vikram Sarabhai Medal in 2016, and Science award of Ministry of Mister of Education of Japan in 2015. He is now Editor-in-Chief of IJACSA and IJISA. http://teagis.ip.is.saga-u.ac.jp/index.html. 